\title{
Antikorruptionsgesetz im Gesundheitswesen ist in Kraft getreten
}

Mitte April hat der Bundestag das viel diskutierte Gesetz zur Bekämpfung von Korruption im Gesundheitswesen, kurz Antikorruptionsgesetz, verabschiedet. Im Juni hat der Bundespräsident es unterschrieben, und der Gesetzestext wurde im Bundesgesetzblatt veröffentlicht. Damit ist das neue Gesetz in Kraft getreten.

Das Antikorruptionsgesetz legt die beiden neuen Straftatbestände der Bestechlichkeit und Bestechung im Gesundheitswesen in den Paragrafen 299a und 299b des Strafgesetzbuches fest. Demnach werden sowohl Bestechung als auch Bestechlichkeit mit einer Geld- oder Freiheitsstrafe von bis zu drei Jahren geahndet. In besonders schweren Fällen kann die Freiheitsstrafe bis zu fünf Jahre betragen. Außerdem wird Korruption im Gesundheitswesen zum Offizialdelikt. Das heißt, dass die Staats- anwaltschaft bereits im Verdachtsfall ermitteln kann und dazu kein Strafantrag notwendig ist. Weiterhin werden Verstöße gegen die Berufsordnungen nun nicht mehr, wie ursprünglich vorgesehen, per se strafrechtlich relevant sein. Das Gesetz schließt eine vom Bundesgerichtshof bereits 2012 erkannte Lücke im Strafgesetzbuch, denn bislang konnten Tätige im Gesundheitswesen nicht nach dem bereits bestehenden Paragrafen 299 belangt werden, weil sie nicht als „Beauftragte“ der Krankenkassen angesehen werden können. Die Berufsordnungen der Mediziner allerdings regelten den Tatbestand der Vorteilsnahme auch bisher schon.

In seiner September-Ausgabe berichtet der DFZ ausführlich über Fakten und Folgen des neuen Antikorruptionsgesetzes.

\section{Private Krankenversicherung}

\section{Laue betont wirtschaftliche Bedeutung}

„Die privaten Krankenversicherungen sind ein wichtiger Bestandteil der deutschen Wirtschaft. Wir leisten einen großen Beitrag.“ Mit diesen Worten hat der Vorsitzende des PKV-Verbandes, Uwe Laue, auf der Jahrestagung in Berlin die finanz- und wirtschaftspolitische Rolle der privaten Krankenkassen herausgestellt.

Die PKV sei im Gesundheitssystem eine starke Säule, Innovationstreiber und nachhaltige Finanzierungsquelle, betonte Laue und bezog sich damit auf das Wirtschaftsforschungsinstitut WifOR, das im Auftrag des Verbandes den „ökonomischen Fußabdruck“ der PKV untersucht. Die Ökonomen sind beim Blick auf die Zahlen von 2015 zu dem Ergebnis gekommen, dass die gesamte Wirtschaft in Deutschland von der Geschäftstätigkeit der PKV profitiert. Nach der WifOR-Untersuchung beläuft sich die sogenannte Bruttowertschöpfung der privaten Krankenversicherer auf 8,6 Milliarden Euro. Die Bruttowertschöpfung ergibt sich aus dem Gesamtwert der im Produktionsprozess erzeugten Waren und Dienstleistungen abzüglich der Vorleistungen.

Verbandschef Laue berichtete, dass jeder Euro in der PKV weitere 2,10 Euro an zusätzlicher Bruttowertschöpfung in an- deren Unternehmen bewirke. Und mit jedem einzelnen Arbeitsplatz seien weitere 4,6 Arbeitsplätze verbunden. In der Autoindustrie seien es zum Vergleich 4,5 zusätzliche Jobs.

Was die Beitragsentwicklung in der PKV betrifft, so widersprach Laue Medienberichten über stark gestiegene PKV-Beiträge. „Was in den meisten Berichten leider nicht stand, war die Tatsache, dass viele Millionen Privatversicherte 2016 gar keine Beitragsanpassung hatten und Hunderttausende sogar Beitragssenkungen erhielten. Und es wurde meistens auch nicht erwähnt, dass die Tarife, in denen es 2016 zu Erhöhungen kam, zum großen Teil jahrelang beitragsstabil waren“, sagte Laue.

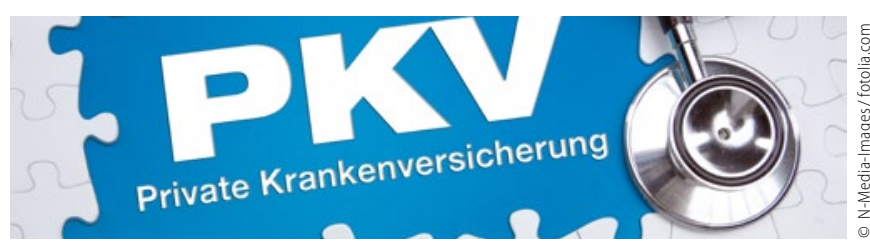

\section{Bundesgesundheitsministerium entscheidet}

\section{„Staatskommissar light" bei der KBV}

Das Bundesgesundheitsministerium (BMG) hat sich in Sachen „Kassenärztliche Bundesvereinigung (KBV)“ gegen den Schritt zur Zwangsverwaltung entschieden. Ganz ohne Aufsicht kommt die KBV allerdings nicht davon: Anstelle des angedrohten Staatskommissars setzt das BMG einen externen Rechtsanwalt ein, der die ungeklärten Immobiliengeschäfte mit der Apotheker- und Ärztebank rund um den Umzug der Körperschaft von Köln nach Berlin aufklären soll. Ende Mai hatte die Vertreterversammlung (VV) der KBV auf Druck des Ministeriums mehrere Beschlüsse gefasst, um der Zwangsverwaltung zu entgehen. Unter anderem einigten sich die Mitglieder der VV darauf, über den Rechtsweg Ruhestandsbezüge und Versorgungsbezüge einiger Mitarbeiter direkt vom Ex-Vorstandsvorsitzenden der KBV, Dr. Andreas Köhler, zurückzufordern. Außerdem stimmte die VV einem Konzept zu, in dem die KBV Antworten auf Fragen zu den ungeklärten Immobiliengeschäften gibt.

„Ziel ist es, in einem strukturierten, kontrollierten und koordinierten Verfahren die festgestellten Rechtsverletzungen ohne weitere Schäden für die KBV und deren Organe zeitnah und ohne weitere Verzögerungen zu regeln“, heißt es in der Vereinbarung zwischen BMG und KBV. Nach Medieninformation geht es beim Immobilienskandal um rund 50 Millionen Euro. cas 